\title{
EVALUASI PERHITUNGAN DAN PENYETORAN PAJAK PENGHASILAN PASAL 22 ATAS PENGADAAN BARANG PADA KANTOR PELAYANAN PERBENDAHARAAN NEGARA (KPPN) KOTAMOBAGU
}

\author{
Zulkarnain Baharta ${ }^{1}$, Inggriani Elim ${ }^{2}$, Heince R. N. Wokas ${ }^{3}$ \\ 1,2,3 Jurusan Akuntansi, Fakultas Ekonomi dan Bisnis, Universitas Sam Ratulangi, Jl. Kampus Bahu, Manado, \\ 95115, Indonesia
}

E-mail: zulkarnainbaharta91@gmail.com

\begin{abstract}
The Indonesian government requires a significant amount of funds for the national development process both at the central and regional levels. For welfare and prosperity, it can help, one of the efforts to realize national development as the case with domestic resources consisting of taxes. One of the taxes set by the government is the tax that is imposed on the tax that is said to be received in the tax year or can also be taxed on translation in part of the tax year. The taxation included in Article 22 of Income Tax is also not part of fiscal policy, because it is a type of tax requested by the government. Article 22 of the procurement tax on the procurement of goods in the municipal treasury office in Kotamobagu is in accordance with the prevailing laws and regulations, taxation regulations and transfers. Descriptive qualitative method used in this study with data collection techniques consisting of interviews, documentation and observation. Data that has been collected from informants is then completed with the stages of data reduction, data presentation and conclusion completion. The results of the study found that KPPN at Kotamobagu City in the PPh article 22 was appropriate and some was not in accordance with Law No. 36 of 2008 concerning tax translation and Regulation of the Minister of Finance No. 34/PMK.010/2017 concerning tax collection Learn article 22 regarding payment or delivery of goods and activities in important fields or business activities in other fields. KPPN is not consistent with Minister of Finance Regulation No. 34/PMK.010/2017 concerning tax collection which addresses article 22.
\end{abstract}

Keywords: calculations; tax; income; PPh 22; KPPN

\section{PENDAHULUAN}

Pemerintah Indonesia membutuhkan biaya tidak sedikit untuk proses pembangunan nasional baik di tingkat pusat maupun di tingkat daerah. Agar kesejahteraan dan kemakmuran rakyat dapat terjaga, salah satu usaha untuk mewujudkan pembiayaan pembangunan nasional tersebut yaitu dengan menggali sumber daya dalam negeri berupa pajak.

Pajak yang ditetapkan pemerintah salah satunya adalah pajak penghasilan yaitu pajak yang dikenakan terhadap subjek pajak atas penghasilan yang diterima atau diperoleh dalam tahun pajak atau dapat pula dikenakan pajak atas penghasilan dalam bagian tahun pajak. Perpajakan yang di dalamnya terdapat unsur Pajak Penghasilan Pasal 22 juga bagian dari kebijakan fiskal, karena merupakan salah satu jenis pajak yang dikenakan oleh pemerintah.

Rakyat Indonesia dan aparat negara jika tidak taat dan sadar akan kewajibannya untuk menyetor dan melaporkan pajak terutangnya, maka kegiatan pemerintah dan kebijakan pemerintah tidak akan berjalan dengan maksimal. Begitu pula dengan pembangunan yang ada di Indonesia, wilayah yang lebih terpencil lebih sulit dijangkau karena tidak adanya dana. Perhitungan Pajak yang akan disetor harus dihitung dengan baik dan benar, kemudian disetorkan ke bank persepsi. Setelah itu dibuat pelaporan pajak oleh wajib pajak ke kantor pajak, namun seringkali penyetoran pajak tidak dilakukan dengan baik oleh wajib pajak. 


\section{TINJAUAN PUSTAKA}

Akuntansi dapat didefinisikan sebagai sebuah sistem informasi yang memberikan kepada para pengguna atau pihak-pihak yang memiliki kepentingan terhadap hasil kinerja dan kondisi keuangan perusahaan. Pemerintah (selaku pengguna eksternal laporan akuntansi), khususnya Direktorat Jenderal Pajak juga membutuhkan informasi akuntansi tersebut sebagai dasar dalam penetapan besarnya pajak terutang (Hery, 2014:1).

American Institute of Certified Public Accounting (AICPA) menjelaskan bahwa akuntansi adalah proses pencatatan, penggolongan, peringkasan dan penyajian secara sistematis dari transaksi-transaksi keuangan suatu badan usaha, serta penafsiran terhadap hasilnya (Priyati, 2013: 1).

Akuntansi adalah seperangkat pengetahuan yang mempelajari perekayasaan dalam penyediaan jasa, yang berupa informasi keuangan kuantitatif dari suatu unit organisasi dan cara penyampaian (pelaporan) informasi tersebut kepada pihak yang berkepentingan untuk dijadikan dasar pengambilan keputusan ekonomi (Pura, 2013: 4).

Pajak adalah iuran kepada negara (yang dapat dipaksakan) yang terutang oleh yang wajib membayarnya menurut peraturan-peraturan, dengan tidak mendapat prestasi kembali, yang langsung dapat ditunjuk, dan yang gunanya adalah untuk membiayai pengeluaranpengeluaran umum berhubung dengan tugas negara yang menyelenggarakan pemerintahan (Waluyo, 2013: 2).

Pajak sebagai suatu kewajiban menyerahkan sebagian dari kekayaan ke kas negara yang disebabkan suatu keadaan, kejadian, dan perbuatan yang memberikan kedudukan tertentu, tetapi bukan sebagai hukuman, menurut peraturan yang ditetapkan pemerintah serta dapat dipaksakan, tetapi tidak ada jasa timbal balik dari negara secara langsung, untuk memelihara kesejahteraan secara umum (Resmi 2013: 1). Pajak adalah iuran rakyat kepada kas negara berdasarkan undang-undang (yang dapat dipaksakan) dengan tiada mendapat jasa timbal (kontraprestasi) yang langsung dapat ditunjukan dan yang digunakan untuk membayar pengeluaran umum (Soemitro, 2007: 11).

Menurut Soemitro (1991:6-7) mengatakan bahwa sebagai suatu hukum, peraturan perpajakan harus memenuhi asas-asas yang mendasari suatu peraturan tersebut, baik berupa falsafah maupun prinsip dasar sebagai berikut, antara lain asas keadilan, asas yuridis, asas kesesuaian dengan tujuan, dan asas nondiskriminasi. Menurut Mardiasmo (2013:9), pajak mempunyai beberapa fungsi, antara lain fungsi anggaran (budgetair), fungsi mengatur (regulerend), fungsi stabilitas, dan fungsi redistribusi pendapatan. Menurut Mardiasmo (2016:9), ada 4 (empat) macam tarif pajak, yaitu tarif sebanding/proporsional, tarif tetap, tarif progresif, dan tarif degresif.

Pajak Penghasilan (PPh) adalah pajak yang dikenakan terhadap Subjek Pajak atas penghasilan yang diterima atau diperolehnya dalam satu tahun pajak (Resmi, 2011:74). Mardiasmo (2011: 226) merupakan pembayaran Pajak Penghasilan dalam tahun berjalan yang di pungut oleh:

1. Bendahara pemerintah termasuk bendahara pada Pemerintah Pusat, Pemerintah Daerah, instansi atau lembaga pemerintah, dan lembaga-lembaga negara lainnya, berkenaan dengan pembayaran atas penyerahan barang, termasuk juga dalam pengertian bendahara adalah pemegang kas dan pejabat lain yang menjalankan fungsi yang sama.

2. Badan-badan tertentu, baik badan pemerintah maupun swasta, berkenaan dengan kegiatan di bidang impor atau kegiatan usaha di bidang lain, seperti kegiatan usaha produksi barang tertentu antara lain otomotif dan semen.

3. Wajib pajak badan tertentu untuk memungut pajak dari pembeli atas penjualan barang yang tergolong sangat mewah. Pemungutan pajak oleh Wajib Pajak badan tertentu ini akan dikenakan terhadap pembelian barang yang memenuhi kriteria tertentu sebagai barang yang tergolong sangat mewah baik dilihat dari jenis barangnya maupun harganya, 
seperti kapal pesiar, rumah sangat mewah, apartemen dan kondominium sangat mewah, serta kendaraan sangat mewah.

Pajak Penghasilan (PPh) Pasal 22 merupakan pembayaran Pajak Penghasilan dalam tahun berjalan yang dipungut oleh bendaharawan pemerintah baik pusat maupun daerah, instansi atau lembaga pemerintah, dan lembaga-lembaga negara lainnya sehubungan dengan pembayaran atas penyerahan barang, atau badan-badan tertentu, baik badan pemerintah maupun swasta berkenaan dengan kegiatan di bidang impor atau kegiatan usaha di bidang lain (Resmi, 2011:271).

Peraturan Kementerian Keuangan (2017) tarif yang berlaku dalam pemungutan $\mathrm{PPh}$ pasal 22 atas pembelian barang yang dibiayai oleh APBN/APBD yaitu: 1,5\% x Harga Pembelian (Tidak termasuk PPN). Apabila Wajib Pajak penerima penghasilan (rekanan) tidak memiliki NPWP maka tarifnya 100\% lebih tinggi dari tarif sebenarnya, yaitu: 3\% $\mathrm{x}$ Harga Pembelian (Tidak termasuk PPN). Pemungutan PPh pasal 22 yang tidak dikenakan $\mathrm{PPh}$ pasal 22 atau dikecualikan dari pemungutan PPh pasal 22 sesuai dengan PMK No.34 Tahun 2017 Pasal 3 adalah :

1. Pembayaran atas pembelian barang oleh pemerintah atau yang lainnya yang jumlahnya paling banyak Rp. 2.000.000,- (dua juta rupiah) dan tidak merupakan pembayaran yang terpecah-pecah.

2. Pembayaran untuk pembelian bahan bakar minyak, listrik, gas, air minum/PDAM, dan benda-benda pos.

3. Pembayaran/pencairan dana Jaring Pengaman Sosial oleh Kantor Perbendaharaan dan Kas Negara.

Direktorat Jenderal Pajak dan Kementerian Keuangan, mengatur penyetoran $\mathrm{PPh}$ pasal 22 sebagai berikut:

a. PPh Pasal 22 dipungut atas pembelian barang sebesar 1,5\% (satu setengah persen) dari harga pembelian pada setiap pelaksanaan pembayaran langsung (LS) oleh KPPN atau Bendahara atas penyerahan barang oleh Wajib Pajak (rekanan).

b. PPh Pasal 22 yang pemungutannya dilakukan oleh Direktorat Jenderal Anggaran, Bendaharawan Pemerintah baik di tingkat Pemerintah Pusat maupun di tingkat Pemerintah Daerah, yang melakukan pembayaran atas pembelian barang, Badan Usaha Milik Negara dan Badan Usaha Milik Daerah, yang melakukan pembelian barang dengan dana yang bersumber dari belanja negara (APBN) dan atau belanja daerah (APBD).

c. Penyetoran dilakukan ke bank persepsi atau Kantor Pos dan Giro, atau pemungutan langsung (LS) oleh KPPN dengan menggunakan SSP yang telah diisi oleh dan atas nama rekanan serta ditandatangani oleh Pemungut.

d. Jika rekanan belum mempunyai NPWP, maka kolom NPWP pada Surat Setoran Pajak (SSP).

Satriawan (2012), menemukan bahwa Ditreskrimum Polda Sulut melalui Bendaharawan Ditreskrimum Polda Sulut sebagaimana diatur dalam Kepmenkeu nomor 254/KMK.03/2001 Ss.t.d.t.d PMK no 210/PMK.03/2008 wajib memungut pajak penghasilan $(\mathrm{PPh})$ pasal 22 sehubungan pembayaran atas penyerahan barang dan telah melakukan perhitungan PPh pasal 22 atas pengadaan barang yang di dananya berasal dari APBN dengan baik atau sesuai dengan ketentuan perpajakan yang berlaku sebesar 1,5\% dari harga pembelian sebelum PPn/PPnBM dan Ditreskrimum Polda Sulut dalam pelaporan PPh pasal 22 belum sepenuhnya sesuai dengan ketentuan perpajakan yang berlaku, seharusnya PPh 22 harus disetor pada saat dilakukan pembayaran sedangkan pelaporannya paling lambat 14 hari setelah masa pajak berakhir.

Mapanawang et al. (2018) menemukan bahwa penerapan perhitungan PPh Pasal 22 atas pembelian barang yang dibiayai dengan APBN di Pengadilan Tata Usaha Negara Manado ada yang tidak sesuai dengan Peraturan Menteri Keuangan Republik Indonesia 
Nomor 107/PMK.010/2015. Sorongan (2014) menemukan bahwa proses pelaporan SPT Masa PPh Pasal 22 atas Pengadaan Barang tidak dilaporkan, tetapi dalam hal perhitungan KPPN Kota Bitung telah melaksanakan sesuai dengan Peraturan Menteri Keuangan PMK No. 210/PMK.03/2008.

Tarigan et al. (2015) menemukan bahwa Kantor Badan Pembangunan Penanaman Modal dan Statistik Daerah Kabupaten Bolaang Mongondow tidak sesuai dengan pedoman peraturan pemerintah saat ini yaitu Peraturan Menteri Keuangan Nomor 154/PMK.03/2010. Wae et al. (2019) menemukan bahwa sesuai dengan Peraturan Menteri Keuangan Republik Indonesia Nomor 107/PMK.010/2015, Kantor Perwakilan Pemda Kabupaten Kepulauan Talaud di Manado wajib memungut Pajak Penghasilan Pasal 22 atas pengadaan barang yang dananya berasal dari APBD sesuai dengan ketentuan perpajakan yang berlaku sebesar 1,5\% dari harga pembelian.

\section{METODE PENELITIAN}

Penelitian ini menggunakan metode penelitian kualitatif deskriptif yaitu berupa studi kasus dan studi pustaka. Jenis data yang digunakan dalam penelitian ini adalah jenis data kualitatif dan kuantitatif. Data kualitatif berupa profil perusahaan Kantor Pelayanan Perbendaharaan Negara Kotamobagu, uraian tugas (job description), kegiatan operasional dan data kepustakaan. Dan data kuantitatif adalah daftar pemungutan PPh pasal 22 atas pengadaan barang, buku pembantu pajak, SSP, pada Kantor Pelayanan Perbendaharaan Negara Kotamobagu. Metode analisis yang digunakan dalam penelitian ini adalah analisis deskriptif yaitu suatu metode yang dilakukan dengan cara mengumpulkan, menyajikan, serta menganalisis data sehingga diperoleh gambaran yang cukup jelas tentang masalah yang dihadapi mengenai mekanisme perhitungan dan pelaporan PPh Pasal 22 atas Pengadaan Barang pada Kantor Pelayanan Perbendaharaan Negara Kotamobagu.

\section{HASIL PENELITIAN DAN PEMBAHASAN}

\subsection{Hasil penelitian}

Hasil penelitian menunjukkan bahwa Pajak Penghasilan Pasal 22 Tahun 2017 pada Kantor Pelayanan Perbendaharaan Negara Kota Kotamobagu terdapat selisih Rp. 245.295 apabila menggunakan PMK Nomor 34/PMK.010/2017.

\subsection{Pembahasan}

Kantor Pelayanan Perbendaharaan Negara (KPPN) Kotamobagu merupakan ujung tombak pelayanan publik dalam jajaran Direktorat Jenderal Perbendaharaan yang ditunjuk oleh pemerintah dalam memungut Pajak Penghasilan Pasal 22 atas setiap transaksi pengadaan barang sesuai dengan Peraturan Menteri Keuangan Republik Indonesia Nomor 34/PMK.010/2017 yaitu dengan harga pembelian barang diatas Rp. 2.000.000 (dua juta rupiah) tidak termasuk PPN dan bukan jumlah yang dipecah-pecah dalam beberapa faktur. Bagi penyedia yang menjadi rekanan yaitu pengusaha yang sudah dikukuhkan menjadi Pengusaha Kena Pajak akan dikenakan tarif 1,5\% dari Dasar Pengenaan Pajak yaitu harga beli sebelum kena PPN dan 3\% bagi pengusaha yang tidak dikukuhkan menjadi Pengusaha Kena Pajak, atau tidak memiliki NPWP sehingga dalam pemberian tarif yang dilakukan oleh bendahara KPPN Kotamobagu telah sesuai dengan peraturan perpajakan yang berlaku. Dasar Pengenaan Pajak (DPP) yang ditetapkan oleh KPPN Kotamobagu adalah merupakan jumlah dari harga pembelian antara kesepakatan kedua belah pihak baik KPPN maupun rekanan.

Hasil penelitian ini sesuai dengan Mapanawang et al. (2018), dimana dari hasil penelitian diketahui bahwa penerapan perhitungan PPh Pasal 22 atas pembelian barang yang dibiayai dengan APBN di Pengadilan Tata Usaha Negara Manado ada yang tidak sesuai dengan Peraturan Menteri Keuangan Republik Indonesia Nomor 107/PMK.010/2015. Berdasarkan wawancara dengan Bendahara Kantor Pelayanan Perbendaharaan Negara 
Kotamobagu didapati bahwa Kantor Pelayanan Perbendaharaan Negara Kotamobagu sudah tidak lagi menggunakan SSP (Surat Setoran Pajak) manual dalam menyetorkan pajaknya, akan tetapi digantikan dengan menggunakan Modul Penerimaan Negara Generasi Kedua (MPN G2). Modul Penerimaan Negara Generasi Kedua ini adalah sistem penerimaan negara yang menggunakan surat setoran elektronik dimana surat setoran elektronik merupakan surat setoran yang berdasarkan pada sistem billing elektronik (e-billing). Penyetoran pajak secara elektronik pada KPPN Kotamobagu dengan menggunakan $e$-billing mulai diberlakukan sejak tahun 2016 dan aplikasinya dapat diakses secara online dengan mengisi formulir surat setoran elektronik di sse.go.id. Penyetoran Pajak Penghasilan Pasal 22 atas Pembelian barang pada KPPN Kotamobagu dilakukan oleh bendahara sebagai wajib pajak menggunakan kode billing yang diterbitkan oleh sistem penerimaan negara. Namun sebelum wajib pajak memperoleh billing pajak, wajib pajak harus mengajukan permohonan e-Fin (electronic filling identification number) dengan datang langsung ke Kantor Pelayanan Pajak dimana wajib pajak terdaftar. Setelah wajib pajak mendapatkan nomor e-Fin, wajib pajak dapat menyetorkan penerimaan negara dengan menggunakan e-billing, Setelah wajib pajak selesai menginput setoran pajak dan telah mendapatkan kode billing, wajib pajak dapat membayar setoran pajak melalui teller bank, kantor pos, ATM, Internet banking atau bisa melalui mobile banking.

Penyetoran PPh Pasal 22 dilakukan pada hari yang sama dengan pelaksanaan pembayaran kepada rekanan pemerintah melalui KPPN. Sistem Penyetoran Pajak dengan $e$ billing (kode billing) sesuai dengan Peraturan Menteri Keuangan Republik Indonesia nomor 34/PMK.010/2017 dimana pemungutan Pajak Penghasilan Pasal 22 oleh pemungut pajak wajib disetor oleh pemungut ke kas Negara melalui Pos Persepsi, Bank Devisa Persepsi, atau Bank Persepsi yang ditunjuk oleh Menteri Keuangan, dengan menggunakan Surat Setoran Pajak yang telah diisi atas nama rekanan serta ditandatangani oleh pemungut pajak dan /atau Bukti Penerimaan Negara yang telah diisi atas nama rekanan.

Berdasarkan hasil penelitian, untuk penyetoran ke pihak bank, bendahara KPPN akan mencetak kode billing terlebih dahulu untuk digunakan pada saat pembayaran. Terdapat beberapa data yang akan diisi pada SSP elektronik yang kurang lebih sama dengan pada saat mengisis SSP manual. Setelah kode billing berhasil dicetak dengan data-data yang sudah diisi dengan benar, maka selanjutnya bendahara menyetorkan pajak terutang ke bank persepsi. Setelah berhasil disetor oleh bendahara, selanjutnya dari pihak bank akan memberikan bukti penyetoran berupa bukti penerimaan negara. Bukti penerimaan negara ini kemudian akan menjadi bukti dalam melaporkan Pajak Penghasilan pasal 22 ke Kantor Pelayanan Pajak.

Adapun berdasarkan Peraturan Menteri Keuangan Republik Indonesia Nomor 34/PMK.010/2017 tentang batas waktu penyetoran pajak dilakukan pada hari yang sama dengan pelaksanaan pembayaran dimana KPPN Kota Kotamobagu hanya sebagian yang telah melaporkan pajak terutangnya tepat waktu yakni dilakukan pada hari yang sama dengan pelaksanaan pembayaran. Hasil penelitian ini sesuai dengan peneliti sebelumnya yang dilakukan oleh Satriawan (2012).

\section{KESIMPULAN DAN SARAN}

\subsection{Kesimpulan}

Hasil penelitian ini menunjukan bahwa KPPN dalam perhitungan Pajak Penghasilan $(\mathrm{PPh})$ Pasal 22, ada yang sesuai dan ada yang tidak sesuai dengan peraturan perpajakan di Indonesia yaitu sesuai dengan UU No. 36 Tahun 2008 tentang pajak penghasilan dan Peraturan Menteri Keuangan No. 34/PMK.010/2017 tentang pemungutan pajak penghasilan pasal 22 sehubungan dengan pembayaran atau penyerahan barang dan kegiatan dibidang impor atau kegiatan usaha dibidang lain. Penyetoran dilakukan dengan tidak tepat waktu oleh KPPN hal ini tidak sesuai dengan Kementerian Keuangan (2017) Peraturan Menteri 
Keuangan Nomor 34/PMK.010/2017 tentang pemungutan Pajak Penghasilan Pasal 22 sehubungan dengan pembayaran atas penyerahan barang dan kegiatan di bidang impor atau kegiatan usaha di bidang lain.

\subsection{Saran}

Saran penelitian ini adalah:

1.Kantor Pelayanan Perbendaharaan Negara Kota Kotamobagu harus selalu fleksibel dan terbuka dalam menerima dan mengikuti setiap arah perubahan peraturan perpajakan yang ditetapkan oleh pemerintah sesuai dengan ketentuan yang berlaku.

2.Kantor Pelayanan Perbendaharaan Negara Kota Kotamobagu harus selalu memperhatikan aturan perpajakan terbaru, agar tidak salah hitung dan salah objek dalam hal menyetor pajak.

3.Kantor Pelayanan Perbendaharaan Negara Kota Kotamobagu harus selalu memperhatikan aturan perpajakan agar dalam hal penyetoran agar selalu tepat waktu dalam penyetoran sesuai dengan aturan yang berlaku.

4.KPPN Kota Kotamobagu sebaiknya menyimpan dengan baik semua data - data yang menyangkut perpajakan sehingga ketika terjadi pemeriksaan oleh Kantor Pajak dikemudian hari bisa dipertanggung jawabkan.

\section{DAFTAR PUSTAKA}

Hery. (2014). Akuntansi perpajakan. Jakarta: PT Grasindo.

Kementerian Keuangan. (2017). Peraturan Menteri Keuangan Nomor 34/PMK.010/2017 tentang pemungutan pajak penghasilan pasal 22 sehubungan dengan pembayaran atas penyerahan barang dan kegiatan di bidang impor atau kegiatan usaha di bidang lain. Jakarta: Kementerian Keuangan Republik Indonesia Direktorat Jenderal Pajak.

Mapanawang, M. A., Sondakh, J., \& Pusung, R. (2018). Evaluasi penerapan PPh Pasal 22 atas pembelian barang yang dibiayai dengan APBN di Pengadilan Tata Usaha Negara Manado. Going Concern: Jurnal Riset Akuntansi, 13(02). 30-37. https://doi.org/10.32400/gc.13.02.19078.2018.

Mardiasmo. (2011). Perpajakan. Yogyakarta: Penerbit Andi.

Mardiasmo. (2013). Perpajakan, Edisi Revisi. Yogyakarta: Penerbit Andi.

Mardiasmo. (2016). Perpajakan, Edisi Revisi. Yogyakarta: Penerbit Andi.

Priyati, N. (2013). Pengantar akuntansi. Jakarta: Indeks.

Pura, R. (2013). Pengantar akuntansi I. Jakarta: Erlangga.

Resmi, S. (2011). Perpajakan teori dan kasus. Jakarta: Salemba Empat.

Resmi, S. (2013). Perpajakan teori dan kasus. Jakarta: Salemba Empat.

Satriawan, M. S. (2012). Analisis peritungan dan pelaporan pajak penghasilan pasal 22 pada

Ditreskrimum Kepolisian Daerah Sulawesi Utara. Skripsi. Fakultas Ekonomi dan Bisnis. Universitas Sam Ratulangi. Manado.

Soemitro. (1991). Asas-asas hukum pajak. Jakarta: Badan Pembina Hukum Nasional.

Soemitro. (2007). Dasar-dasar hukum pajak pendapatan. Jakarta: Salemba Empat.

Sorongan, C. T. (2014). Perhitungan dan pelaporan Pajak Penghasilan Pasal 22 atas pengadaan barang pada Kantor Pelayanan Perbendaharaan Negara Kota Bitung. Jurnal EMBA: Jurnal Riset Ekonomi, Manajemen, Bisnis dan Akuntansi, 2(1). 704714. https://ejournal.unsrat.ac.id/index.php/emba/article/view/4385

Tarigan, M. E. R., Morasa, J., \& Elim, I. (2015). Perhitungan dan pelaporan Pajak Penghasilan Pasal 22 atas pengadaan barang pada Kantor Badan Perencanaan Pembangunan Penanaman Modal dan Statistik Daerah Kabupaten Bolaang Mongondow. Jurnal Berkala Ilmiah Efisiensi, 15(3), 152-167. https://ejournal.unsrat.ac.id/index.php/jbie/article/view/9357 
Wae, D., Sabijono, H., \& Lambey, R. (2019). Analisis perhitungan dan pemotongan PPh pasal 22 atas pengadaan barang pada Kantor Perwakilan Pemda Kabupaten Kepulauan Talaud di Manado. Indonesia Accounting Journal, 1(2), 81-89. https://doi.org/10.32400/iaj.26664

Waluyo. (2013). Perpajakan Indonesia. Jakarta: Salemba Empat. 